\title{
Lightweight cementitious composites containing cenospheres and polypropylene fibres after exposure to high temperatures
}

\author{
Wojciech Szymkuć1,*, and Piotr Tokłowicz ${ }^{2}$ \\ ${ }^{1}$ Institute of Structural Analysis, Poznan University of Technology, Poznań, Poland \\ ${ }^{2}$ Independent Researcher, Poznan University of Technology Alumnus, Poznań, Poland
}

\begin{abstract}
The paper presents the results of experimental investigation of lightweight cementitious composites with cenospheres (LCCC) exposed to high temperatures. We showed the positive effect of cenospheres on postfire residual compressive strength in previous papers. This paper focuses on the LCCC with the addition of polypropylene (PP) fibres. Specimens are heated up to $400,600,800,1000$ and $1200{ }^{\circ} \mathrm{C}$. Then they are cooled to ambient temperature and their residual flexural and compressive strength is tested. The results are compared with non-heated specimens with compressive strength above $50 \mathrm{MPa}$. For plain LCCC composites, the results show significant improvement of residual compressive strength in comparison with typical concretes. No significant changes of compressive strength are found after exposure to temperatures up to $600^{\circ} \mathrm{C}-$ more than $85 \%$ of the residual compressive strength is retained after exposure to this temperature for both mixes. Polypropylene fibres are found to be a successful mean to mitigate spalling without significantly lowering neither ambient nor residual compressive strength. Moreover, designed composite has low density and low thermal conductivity at room temperature.
\end{abstract}

\section{Introduction}

Concrete structures can withstand fire for relatively long time periods due to low thermal diffusivity of concrete and the size of cross-sections. However, like steel, concrete exhibits reduction of its mechanical parameters at elevated temperatures. In general, concrete does not regain strength after heating. This means that residual tests might be good indicator of strength at elevated temperature. One possible way to obtain heat-resistant concrete is using High Alumina Cement or geopolymers concrete.

The paper presents experimental results regarding lightweight cementitious composites with cenospheres and polypropylene fibers. Cenosphere has its own special properties, that are in demand when fire resistance is considered: low thermal conductivity and high thermal stability. Cenosphere (or microsphere) is a hollow silica and alumina sphere with a diameter less than $0.5 \mathrm{~mm}$. Microsphere is a by-product of coal combustion in thermal

\footnotetext{
*Corresponding author: wojciech.szymkuc@put.poznan.pl
} 
power plants. The most important characteristics of microspheres are low bulk density (about $400 \mathrm{~kg} / \mathrm{m}^{3}$ ), low thermal conductivity at room temperature $0.1 \mathrm{~W} /(\mathrm{m} \cdot \mathrm{K})[1]$, low coefficient of thermal expansion $\left(6.13 \cdot 10^{-6} 1 / \mathrm{K}\right)$ according to [2] and high melting temperature, which is above $1200{ }^{\circ} \mathrm{C}$.

One of the most important sectors for cenosphere utilisation is oil industry. The first mentions of cement-based composites with cenospheres can be found in patents from early 1970's. Cenospheres are used in refractories [3], in production of paints and insulating materials, such as intumescent coatings [2].

One of the causes of concrete damage at high temperature is microcracking due to thermal incompatibility between the aggregate and cement paste [4]. Using aggregates with lower coefficient of thermal expansion is beneficial for strength at elevated temperature [5]. Since thermal expansion of cenosphere is less than a half of expansion of ordinary concrete, better compatibility between the constituents of the proposed composite was expected and led to results presented in [6]. Mechanical properties of similar composite before and after exposure to elevated temperature were also studied by Huang et al. [7].

A mix of cement, water and cenosphere was probably first proposed by Gebhardt (patent US3782985A: Lightweight, high strength concrete and method for manufacturing the same, with cement to cenosphere ratios between $0.2: 1$ to $4: 1$ ), later studied by Montgomery \& Diamond [8] with cement to cenosphere to water ratio of 1:0.43:0.5. Liu et al. [9] proposed a mix with silica fume and superplasticiser and studied water and chloride ion penetration resistance of lightweight cementitious composite with cenosphere. Since then, the mix developed by [9] was a base for other researchers $[6,7,10]$.

\section{Materials}

\subsection{Mix composition}

The LCCC consists of Portland cement CEM 42.5R, silica fume, cenospheres, water and superplasticizer. The mix proportions by weight are presented in Tab. 1. First, cement is mixed with silica fume, then water with superplasticizer is added, followed by air-dry cenosphere. With low amount of water, cenosphere requires more than 15 minutes of mixing time to achieve desired flow. Polypropylene fibres are added during last stage of mixing.

Table 1. Mix proportions by weight.

\begin{tabular}{|c|c|c|c|c|c|}
\hline Water & Cement & Silica Fume & Cenospheres & Superplasticiser & PP fibres \\
\hline 0.277 & 0.92 & 0.08 & 0.45 & $2.5 \%$ cement mass & $1.8 \mathrm{~kg} / \mathrm{m}^{3}$ \\
\hline
\end{tabular}

The mix proportions presented in Tab. 1 is an outcome of literature research and further tailoring for the intended use. With relation to research described in the Introduction section, we initially focused on lowering the water to cement ratio, and cenosphere and superplasticizer selection, that would yield a target flow, high compressive strength and low density.

The loose bulk density of cenospheres is $410 \mathrm{~kg} / \mathrm{m}^{3} .83 \%$ of particles are between 125 and $250 \mu \mathrm{m}$, with no particles exceeding $500 \mu \mathrm{m}$. Cenosphere can be considered as aggregate in this mix. Loose cenosphere can be seen in Fig. 1 (a), while cenosphere embedded in cement paste is presented in Fig. 1 (b) and (c). 

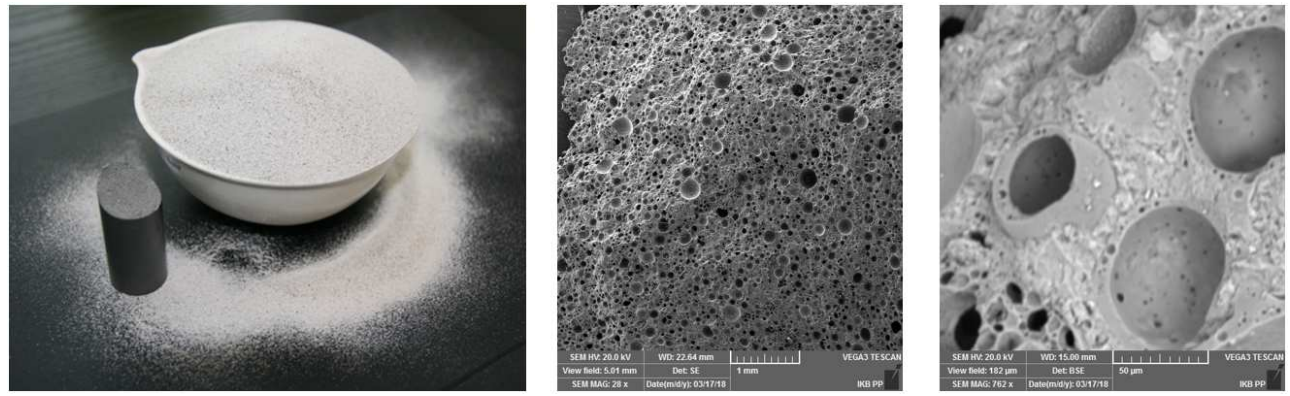

Fig. 1. a) loose cenosphere and $\varphi 12 \mathrm{~mm}$ cylinder sample, b) overview of composite structure,

c) magnification of cenospheres in cement paste before heating. More images are available in [11].

\subsection{Specimen details, casting and curing}

Specimens were prepared using a standard mixer (EN 196-1). Because there was no coarse aggregate in the mix, prism specimens $4 \times 4 \times 16 \mathrm{~cm}$ were cast. Specimens were demoulded 24 hours after casting, then kept in water for 27 days. Then they were removed from water and kept in laboratory conditions for about 12 months. Such long conditioning time was a result of a laboratory schedule. First tests were made on specimens without PP fibres and without oven-drying. The results are not included in this paper, however it must be noted that due to high moisture content (about $11 \%$ by weight), out of four specimens, one exploded due to spalling (Fig. 2). In order to mitigate spalling, polypropylene fibres were added. None of the tested specimens with PP fibres spalled.
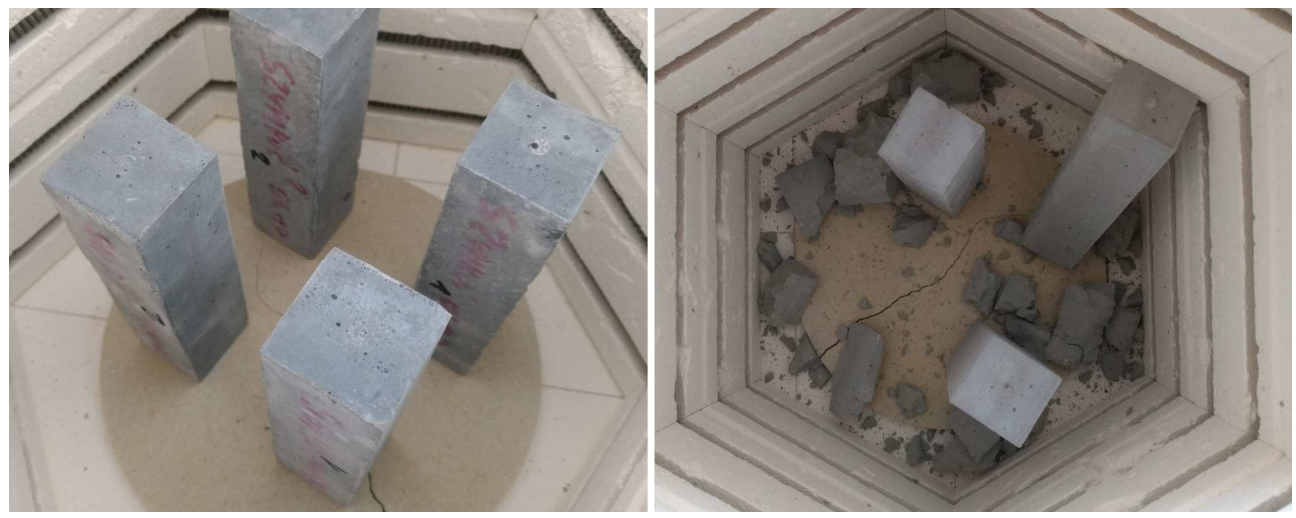

Fig. 2. The results of initial research. Specimens without PP fibres before and after heating.

\section{Methods}

Flow was determined using the flow table (EN 1015-3). Unloaded specimens were heated in an electric furnace with a heating rate of $5{ }^{\circ} \mathrm{C} / \mathrm{min}$. After reaching the target temperature $\left(400,600,800,1000\right.$ or $\left.1200{ }^{\circ} \mathrm{C}\right)$, it was kept constant for 60 minutes. Then the furnace was shut off and the specimens were kept inside until the next day. All specimens were tested next day after heating. Density and flexural strength were determined based on results from three specimens for each temperature. Prisms were first used to determine flexural strength, then six halves of the prisms were used to determine the compressive strength. Flexural and compressive strength before and after heating were determined 
following the procedure described in EN 196-1. Thermal diffusivity was evaluated using the procedure described in [9].

\section{Results and discussion}

\subsection{Material properties at ambient temperature}

Designing a mix with a flow of $120 \mathrm{~mm}$ allowed to obtain good workability. The density without oven-drying was equal to $1305 \mathrm{~kg} / \mathrm{m}^{3}$. The flexural and compressive strength of non-heated specimens were 6.0 MPa and $53.8 \mathrm{MPa}$, respectively. Those values are different than previously reported [6], however the differences can be explained by slight increase of cenosphere content, specimen age at the day of testing and inclusion of polypropylene fibres.

\subsection{Material properties after exposure to elevated temperature}

\subsubsection{Mechanical properties}

Specimen density, flexural strength and compressive strength are reported in table 2. It can be seen, that total mass loss during heating is about $16 \%$, and most of the losses occur between 20 and $800{ }^{\circ} \mathrm{C}$. There is a slight density increase at $1000{ }^{\circ} \mathrm{C}$, however this can be explained by higher mass of specimens destined to be tested at this temperature (their mean mass was 3 grams higher than mass of specimens prepared for tests after exposure to 800 $\left.{ }^{\circ} \mathrm{C}\right)$. Relatively high density change results from high cement paste content in the mix and high moisture content.

The residual strength (in per cent) related to strength at room temperature is presented in Fig. 3. Each result after exposure to high temperature is an average of six compressive strength tests.

The influence of elevated temperature on flexural strength is presented in Tab. 2 and Fig. 3. Exposure to elevated temperature results in a $50 \%$ loss of flexural strength. The results after heating to $1200{ }^{\circ} \mathrm{C}$ indicate small increase of strength when compressed to $1000{ }^{\circ} \mathrm{C}$.

Table 2. Flexural and compressive strength after exposure to elevated temperature.

\begin{tabular}{|c|c|c|c|}
\hline $\begin{array}{c}\text { Temperature } \\
{\left[{ }^{\circ} \mathbf{C}\right]}\end{array}$ & $\begin{array}{c}\text { Density } \\
{\left[\mathbf{k g} / \mathbf{m}^{\mathbf{3}}\right]}\end{array}$ & $\begin{array}{c}\text { Flexural strength } \\
{[\mathbf{M P a}]}\end{array}$ & $\begin{array}{c}\text { Compressive strength } \\
{[\mathbf{M P a}]}\end{array}$ \\
\hline 20 & 1305 & 6.0 & 53.8 \\
\hline 400 & 1151 & 3.8 & 48.2 \\
\hline 600 & 1138 & 4.1 & 45.5 \\
\hline 800 & 1096 & 2.9 & 34.7 \\
\hline 1000 & 1097 & 3.0 & 27.8 \\
\hline 1200 & 1094 & 4.8 & 19.7 \\
\hline
\end{tabular}

The most important results in this work concern the compressive strength. It can be seen in Tab. 2 and Fig. 3, that LCCC with PP fibres presents high retention of compressive strength. The strength loss is less than $15 \%$ after exposure to $600{ }^{\circ} \mathrm{C}$. When the specimens were exposed to $800{ }^{\circ} \mathrm{C}$ and subsequently cooled down to ambient temperature, their residual strength was $34.7 \mathrm{MPa}$. Further research at higher temperatures (1000 and 
$1200{ }^{\circ} \mathrm{C}$ ) revealed that the residual strength at those temperatures is $53 \%$ and $37 \%$, respectively.

According to the frequently cited Eurocode 1992-1-2, the compressive strength of concrete is about a half of its initial value at $600{ }^{\circ} \mathrm{C}$. Temperature $1000{ }^{\circ} \mathrm{C}$ and above results in retention factors for compressive strength less than $10 \%$.

Figure 3 presents the results in terms of relative (in per cent) residual compressive and flexural strengths. Additionally, results of previous research without PP fibres [6] are presented for comparison. It can be noticed that PP fibres did not have a significant effect on neither compressive nor flexural strength. The intended role of PP fibres in the mix was to mitigate spalling. In our previous research [6], specimens without PP fibres and without oven-drying, have shown evidence of spalling (Fig. 2). Other differences between previous and current research is the conditioning time (6 months previously, and 12 months now), a slight adjustment of cenosphere content $(0.42$ previously and 0.45 now, see Tab. 1$)$ and maximum temperature raised to $1200{ }^{\circ} \mathrm{C}$.

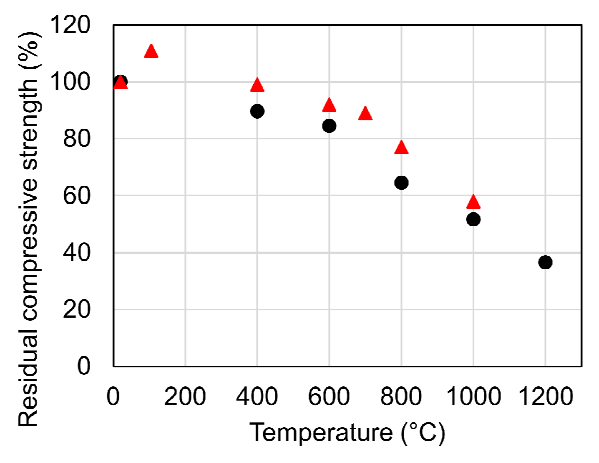

- With PP fibres $\quad \Delta$ Without PP fibres [6]

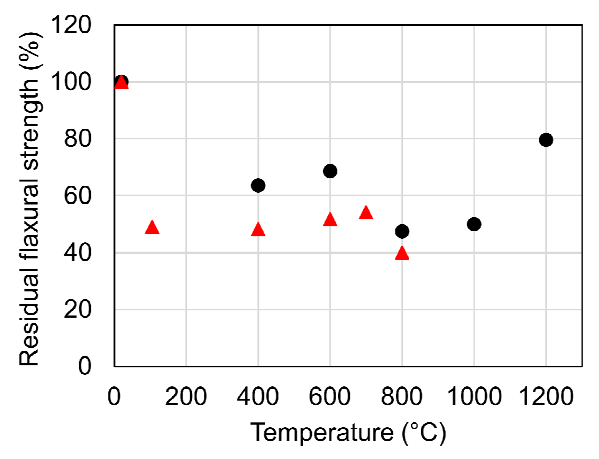

- With PP fibres $\quad \Delta$ Wihout PP fibres [6]

Fig. 3. Residual compressive (left) and flexural (right) strength of specimens with PP fibres (this research, not oven-dried) and without PP fibres (previous research [6], oven-dried at $105^{\circ} \mathrm{C}$ ).

Some issues that could be addressed in further research are (1) sensitivity of LCCC to heating rates, (2) influence of specimen shape and size on strength reduction and (3) strength at elevated temperature. Those problems will be addressed in another paper.

Images of two samples: standard mortar (EN 196-1) and LCCC after heating according to the standard temperature-time curve up to $800{ }^{\circ} \mathrm{C}$ and keeping samples at this temperature for an hour, can be found in Fig. 4. Large, visible cracks can be seen on the surface of standard mortar, while no cracks are visible on the surface of LCCC.
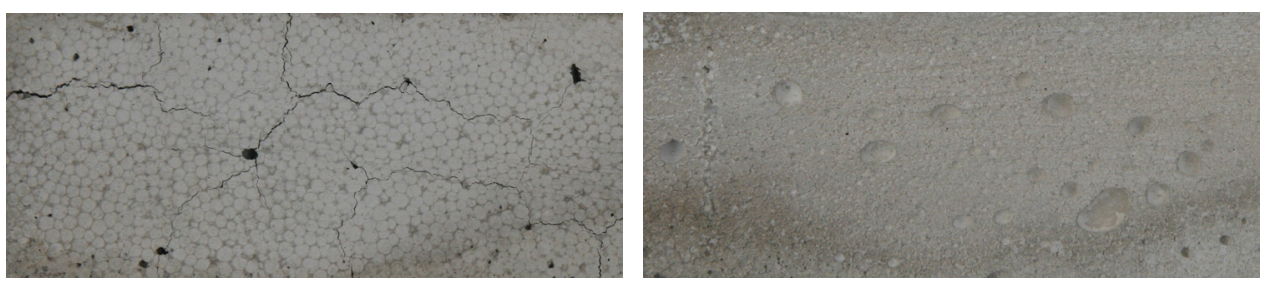

Fig. 4. Specimen surface after fast heating up to $800^{\circ} \mathrm{C}$. Left: reference standard mortar (EN 196-1) specimen with visible cracks, Right: LCCC without cracks.

The interface transition zone between cenosphere and cement paste was evaluated using SEM before and after exposure to $600{ }^{\circ} \mathrm{C}[6,8]$. The interface seems to be unaffected by exposure to $600{ }^{\circ} \mathrm{C}$ and there are no visible cracks. SEM images can be found in [11]. 


\subsubsection{Thermal properties}

Our previous research for a similar mix has shown low thermal conductivity $0.6 \mathrm{~W} /(\mathrm{m} \cdot \mathrm{K})$ for non-oven dried specimens, using the TPS method. The specific heat, measured with DSC, was comparable to ordinary concretes. For the mix studied in this paper, we have measured the thermal diffusivity, using the procedure described in [12]. Thermal diffusivity was measured in two heating cycles on the same cylindrical $(100 \times 200 \mathrm{~mm})$ sample. The heating rate was $2{ }^{\circ} \mathrm{C} / \mathrm{min}$, up to $350{ }^{\circ} \mathrm{C}$. Temperatures inside cylinder were measured using K-type thermocouples. During the first heating cycle, measured thermal diffusivity was between 0.2 and $0.4 \mathrm{~mm}^{2} / \mathrm{s}$. After the first heating, most of the water evaporated, which resulted in thermal diffusivity between 0.35 and 0.45 in during the second heating.

\section{Conclusions}

The studied lightweight cementitious composite with cenospheres offers good insulation and remarkable post-fire strength retention. The results show significant improvement of residual compressive strength, when compared to ordinary concretes. We have observed no significant changes of strength after exposure to temperatures up to $600{ }^{\circ} \mathrm{C}$. After exposure to 1000 and $1200{ }^{\circ} \mathrm{C}$, about $50 \%$ and $40 \%$ of strength was retained, respectively. The addition of polypropylene fibres $\left(1.8 \mathrm{~kg} / \mathrm{m}^{3}\right)$ successfully mitigated spalling. Due to presence of cenospheres, the composite has low thermal diffusivity. Those results, together with relatively high strength at ambient conditions, indicate it might be worth exploring the fire performance of structural members in future research.

The authors wish to express their gratitude and sincere appreciation to Paulina Szymkuć for her help with casting the specimens for this research.

\section{References}

1. W. Pichór, Composites 6 (3), 71-77 (2006)

2. A. Arizmendi-Morquecho, A. Chávez-Valdez, J. Alvarez-Quintana, Appl. Therm. Eng. 48, 117-121 (2012)

3. I. Pundienè, A. Korjakins, J. Pranckevičienè, M. Kligys, Ceram. Int. 44 (13), 1594415953 (2018)

4. K. Krzemień, I. Hager, Constr. Build. Mater. 96, 155-163 (2015)

5. G.A. Khoury, Y. Anderberg, K. Both, J. Fellinger, N.P. Høj, C. Majorana, fib Bulletin No. 38: Fire design of concrete structures - materials, structures and modelling (2007)

6. W. Szymkuć, P. Tokłowicz, A. Glema, H. Craveiro, Proceedings of the 10th International Conference on Structures in Fire (585-592, 2018)

7. Z. Huang, K. Padmaja, S. Li, J. Y. R. Liew, Constr. Build. Mater. 164, 760-774 (2018).

8. D. Montgomery, S. Diamond. Cem. Concr. Res. 14 (6), 767-775 (1984).

9. X. Liu, K. S. Chia, M. H. Zhang, R. J. Y. Liew, Proceedings of International Congress on Durability of Concrete (ICDC2012)

10. Z. Chen, K. Li, E. Yang, Proceedings of the 9th International Conference on Fracture Mechanics of Concrete and Concrete Structures (https://doi.org/10.21012/FC9.130)

11. W. Szymkuć, P. Tokłowicz, A. Glema, H. Craveiro, Replication data https://doi.org/10.7910/DVN/Z7KME7, Harvard Dataverse, V1 (2018).

12. R. Felicetti, P. G. Gambarova, P. Bamonte, Fire Mater. 37 (3), 200-216 (2012). 